\title{
Laser excited novel near-infrared photoluminescence bands in fast neutron-irradiated $\mathrm{MgO} \cdot n \mathrm{Al}_{2} \mathrm{O}_{3}$
}

\author{
Abu Zayed Mohammad Saliqur Rahman ${ }^{\mathrm{a}, \mathrm{b}, *}$, A. S. M. A. Haseeb ${ }^{\mathrm{b}}$, Qiu Xu ${ }^{\mathrm{c}}$, \\ Jarah Evslin ${ }^{\mathrm{d}}$, Marco Cinausero ${ }^{\mathrm{e}}$ \\ ${ }^{a}$ Institute of High Energy Physics, Chinese Academy of Sciences \\ 19B Yuquanlu Shijingshan District Beijing 100049, China \\ ${ }^{b}$ Department of Mechanical Engineering, University of Malaya \\ 50603 Kuala Lumpur, Malaysia \\ ${ }^{c}$ Reactor Research Institute, Kyoto University \\ 2, Asashiro-Nishi, Kumatori-cho, Sennan-gun, Osaka 590-0494, Japan \\ ${ }^{d}$ Institute of Modern Physics, Chinese Academy of Sciences \\ Nanchanglu 509, Lanzhou 730000, China \\ e Laboratori Nazionali di Legnaro, Istituto Nazionale di Fisica Nucleare \\ Viale dell Universita, 2, 35020 Legnaro Padova, Italy
}

\begin{abstract}
New near-infrared photoluminescence bands were observed in neutron-irradiated spinel single crystal upon excitation by a $532 \mathrm{~nm}$ laser. The surface morphology of the unirradiated and fast neutron-irradiated samples was investigated using atomic force microscopy and scanning probe microscopy. Fast neutronirradiated samples show a strong emission peak at 1,685 $\mathrm{nm}$ along with weak bands at 1,065 and 2,365 nm. The temperature dependence of the photoluminescence intensity was also measured. At lower temperatures, the dominant peak at $1,685 \mathrm{~nm}$ shifts toward lower energy whereas the other peaks remain fixed. Activation energies of luminescence quenching were estimated to be 5.7 and $54.6 \mathrm{meV}$ for the lower and higher temperature regions respectively.

Keywords: near-infrared photoluminescence, point defects, neutron-irradiation, $\mathrm{MgO} \cdot n \mathrm{Al}_{2} \mathrm{O}_{3}$

\footnotetext{
* Corresponding author

Email address: zayed@ihep.ac.cn, zayed@um.edu.my (Abu Zayed Mohammad Saliqur Rahman)
}

Preprint submitted to Radiation Physics and Chemistry

March 31, 2016

C) 2016. This manuscript version is made available under the Elsevier user license http://www.elsevier.com/open-access/userlicense/1.0/ 


\section{Introduction}

Magnesium aluminate spinel $\left(\mathrm{MgAl}_{2} \mathrm{O}_{4}\right)$ is a radiation hard oxide material. Due to its resistance to radiation, it is a candidate material for very important applications such as window materials, liquid metal cooling systems, inert matrix fuel and insulating materials in advanced fusion reactor technology[14]. Spinel has excellent thermal and mechanical properties which can be easily activated by various metal ions for applications in optical devices [5-7] and scintillators $[8,9]$. For applications of spinel crystals in scintillators and thermoluminescence dosimetry, an understanding of its irradiation-induced defects is essential [10]. Spinel has a cubic cell crystal structure with Fd3m symmetry, containing a close-packed array of 32 oxygen atoms [11, 12]. Due to the complex crystal structure of spinel, a study of its defects is more difficult than in the case of its constituent oxides $\mathrm{MgO}$ and $\alpha-\mathrm{Al}_{2} \mathrm{O}_{3}$.

Many studies have already been conducted on optical, dielectric and mechanical properties of irradiated $\mathrm{MgAl}_{2} \mathrm{O}_{4}$ [13-21]. In our previous study, we observed the vibronic photoexcitation spectra in both neutron- and electronirradiated spinel [22]. Temperature dependences of simple $\mathrm{F}$ centers and $\mathrm{F}$ aggregate centers related to photoexcitation and photoluminescence spectra in

neutron irradiated $\alpha-\mathrm{Al}_{2} \mathrm{O}_{3}$ single crystal were reported as well [23, 24]. Despite a wealth of studies of irradiation-induced defects in spinel such as simple color centers (F centers) [25], many characteristics of the evolution of simple defects into aggregates or colloid formation are not yet understood. Regardless of the matrix, only a handful of studies was reported on the irradiation-induced formation of metallic colloids in insulating materials [26-29]. Understanding such defect evolution is not only interesting for fundamental reasons but also for applications because colloid formation may degrade the insulating properties of the material.

In this study we have used laser-based near-infrared (NIR) luminescence to characterize the irradiation-induced defects in spinel. Laser-based NIR spectroscopy is a non-destructive technique to measure defect and impurity related 
luminescence. Previously, we have investigated neutron-irradiation induced near-infrared luminescence in $\alpha-\mathrm{Al}_{2} \mathrm{O}_{3}[30,31]$. However, to the best of our knowledge, there is almost no information on irradiation-induced near-infrared luminescence in spinel single crystal. In this article, we report novel laser-excited NIR photoluminescence bands in neutron-irradiated spinel single crystals. We also estimate the activation energies of the luminescence quenching mechanism by using the temperature dependence of the photoluminescence band.

\section{Experimental}

Monocrystals of undoped non-stoichiometric magnesium aluminate spinel $\left(\mathrm{MgO} \cdot n \mathrm{Al}_{2} \mathrm{O}_{3}\right) \quad(n=2)$ grown using the Czochralski method were obtained from the Furuuchi Chemical Corporation of Japan. The typical size of the samples was $7 \times 5 \times 1 \mathrm{~mm}^{3}$. Samples were irradiated by fast neutrons $\left(E_{n}\right.$ $>0.1 \mathrm{MeV}$ ) at various temperatures and fluences using the Low Temperature Loop (LTL) and Hydraulic Exposure Tube (HET) facilities at the Kyoto University Research Reactor Institute (KURRI) and the Japan Material Testing Reactor (JMTR). Total irradiation doses ranged from $1.3 \times 10^{17}$ to $1.2 \times 10^{20}$ $\mathrm{n} / \mathrm{cm}^{2}$, which corresponds to a $6.9 \times 10^{-5}$ to $6.4 \times 10^{-2}$ displacement per atom (dpa) estimated using an average displacement energy of $52 \mathrm{eV}$ [32]. Table 1 shows the neutron irradiation conditions of the samples. Electron-irradiation was performed at liquid nitrogen temperature using an electron linear accelerator (KURRI-LINAC). The energy of the electron beam was $30 \mathrm{MeV}$ with a fluence of $5.8 \times 10^{18} \mathrm{e} / \mathrm{cm}^{2}$ at a flux of $1.6 \times 10^{14} \mathrm{e} / \mathrm{cm}^{2}$. sec.

NIR emission spectra were measured in the 800-3000 $\mathrm{nm}$ range using an iHR320 spectrometer with increments of $4 \mathrm{~nm}$. Entrance and exit slits for laser light were set at $4 \mathrm{~mm}$ for all of the measurements. A semiconductor laser with a wavelength of $532 \mathrm{~nm}$ was used as an excitation source. A PbSe detector was used to detect photons in the infrared spectral range. The temperature dependence of the NIR photoluminescence spectra was monitored at temperatures ranging from 13.6 to $300 \mathrm{~K}$. Atomic force microscopy (AFM) and 
Table 1: Neutron-irradiation conditions of the single crystal $\mathrm{MgO} \cdot n \mathrm{Al}_{2} \mathrm{O}_{3}(n=2)$

\begin{tabular}{lllll}
\hline $\begin{array}{l}\text { Irradiation } \\
\text { Facility }\end{array}$ & $\begin{array}{l}\text { Neutron flux } \\
\left(\Phi_{f}\right)\left(\mathrm{n} / \mathrm{cm}^{2} \mathrm{~s}\right)\end{array}$ & $\begin{array}{l}\text { Fluence } \\
\left(\mathrm{n} / \mathrm{cm}^{2}\right)\end{array}$ & $\begin{array}{l}\text { Displacement } \\
\text { per atom }(\mathrm{dpa})\end{array}$ & $\begin{array}{l}\text { Atmosphere/ } \\
\text { irradiation } \\
\text { temperature } \\
(\mathrm{K})\end{array}$ \\
\hline JMTR & $6.3 \times 10^{13}$ & $1.2 \times 10^{20}$ & $6.4 \times 10^{-2}$ & $\mathrm{He} / 470$ \\
HET-10 & $3.9 \times 10^{13}$ & $1.4 \times 10^{18}$ & $7.4 \times 10^{-4}$ & $\mathrm{He} / 360$ \\
HET-5 & $3.9 \times 10^{13}$ & $7.0 \times 10^{17}$ & $3.7 \times 10^{-4}$ & $\mathrm{He} / 360$ \\
LTL & $4.8 \times 10^{11}$ & $1.3 \times 10^{17}$ & $6.9 \times 10^{-5}$ & $\mathrm{He} / 20$ \\
\hline
\end{tabular}

Scanning Probe Microscopy (SPM) were used to map the surface morphology of the neutron-irradiated and unirradiated samples.

\section{Results and discussion}

Figure 1 shows the AFM and SPM images of the surfaces of unirradiated $(\mathrm{a}, \mathrm{c})$ and neutron-irradiated $(\mathrm{b}, \mathrm{d})$ spinel monocrystals. The difference between the two surfaces is very clearly caused by neutron-irradiation. The surface is heavily damaged during neutron irradiation. Figure 2 shows the NIR photoluminescence spectra of unirradiated, electron- and neutron irradiated spinel monocrystal. The unirradiated sample shows almost no emission in the 850$3,000 \mathrm{~nm}$ range except for a very weak broad band in the range of 1,500-2,000 $\mathrm{nm}$. This broad peak in the unirradiated sample may result from pre-existing defects. The electron-irradiated sample as well as the sample irradiated by neutrons while at a low temperature both exhibit trivial emission at 1,650 nm. A strong emission peak at 1,685 $\mathrm{nm}$ with weak bands at 1,065 and 2,365 $\mathrm{nm}$ was observed after neutron-irradiation at higher temperatures. The highest photoluminescence intensity can be observed after neutron-irradiation at a fluence of $7.0 \times 10^{17} \mathrm{n} / \mathrm{cm}^{2}$. 
(a)

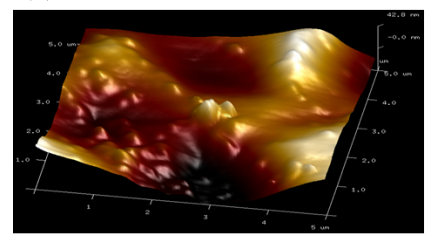

(c)

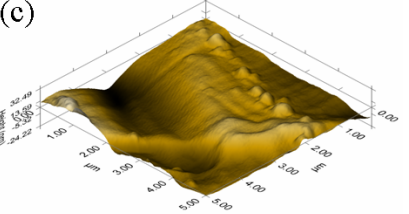

(b)

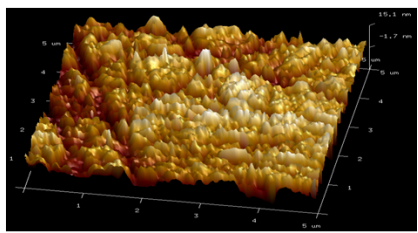

(d)

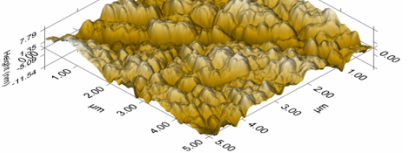

Figure 1: (Color online) AFM (a,b) and SPM (c,d) 3-D images of surface for unirradiated $(\mathrm{a}, \mathrm{c})$ and neutron-irradiated (b,d) spinel single crystal. Scalings of AFM and SPM images are $5 \times 5$ and $4 \times 4 \mu \mathrm{m}$ respectively.

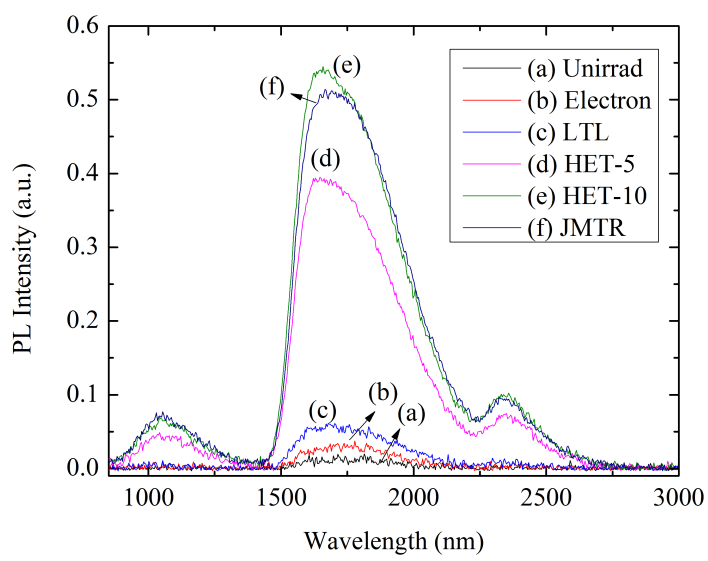

Figure 2: (Color online) NIR PL spectra of unirradiated, electron- and neutron-irradiated spinel single crystal at various fast neutron fluences. The excitation wavelength was $532 \mathrm{~nm}$. 
As the photoluminescence bands are hardly seen in the unirradiated samples, they are probably the result of neutron-irradiation. Fast neutrons can create atomic displacement defects such as anion and cation vacancies in spinel single crystals. Therefore the photoluminescence bands could be primarily caused by atomic displacement defects. Positive ion vacancies $\left(\mathrm{Al}^{3+}\right.$ or $\left.\mathrm{Mg}^{2+}\right)$ act as a center of negative charge and thus cannot trap electrons. Al monovacancy can be detected by positron annihilation spectroscopy[33]. In oxide materials, defect related luminescence usually comes from electron centers such as F or F aggregate centers. The KURRI LTL facility efficiently produces simple color centers such as $\mathrm{F}$ and $\mathrm{F}^{+}[34]$.

The purpose of neutron-irradiation at low temperatures is to suppress the formation of $\mathrm{F}$ aggregate centers. At higher temperature, during fast neutron irradiation simple $\mathrm{F}$ type centers evolve into $\mathrm{F}$ aggregate centers. Thus the concentrations of $\mathrm{F}$ centers is reduced, which eventually yields different photoluminescence bands as a sign of $\mathrm{F}$ aggregate center formation. In this case, these photoluminescence bands may be attributed to F aggregate centers. Although much more intensive research is necessary to assign these bands accurately, we believe that it is interesting to report the new photoluminescence bands here.

Temperature dependence measurements of the NIR photoluminescence bands were conducted to understand the nature of these bands in more detail. Figure 3 shows the temperature dependence of the dominant NIR photoluminescence band at 1,685 $\mathrm{nm}$ along with the weaker bands at 1,065 and 2,365 $\mathrm{nm}$ for the sample irradiated up to a neutron fluence of $1.2 \times 10^{20} \mathrm{n} / \mathrm{cm}^{2}$ at a temperature range of 13.6 to $300 \mathrm{~K}$. Carefully examining the photoluminescence peaks, one observes that at lower temperatures $(<180 \mathrm{~K})$ the peak at $1,685 \mathrm{~nm}$ with a full width half maxima (FWHM) of $445 \mathrm{~nm}$ shifts towards lower energies and reaches 1,747 nm with a FWHM of $166 \mathrm{~nm}$ at $13.6 \mathrm{~K}$. Luminescence peak positions and FWHM at 13.6 and $300 \mathrm{~K}$ are given in table 2 for comparison. Usually, at lower temperature peaks shift towards higher energy due to a reduction of electron-phonon interactions. However, in this case, the shift occurs in the opposite direction. This shift may be caused by a different band which 


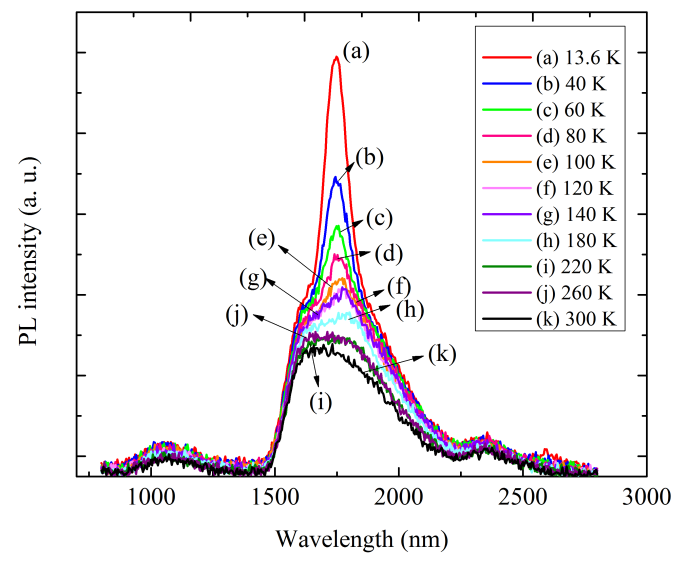

Figure 3: (Color online) NIR photoluminescence spectra of neutron-irradiated (JMTR) spinel single crystal at temperatures ranging from 13.6 to $300 \mathrm{~K}$. The excitation wavelength was 532 nm.

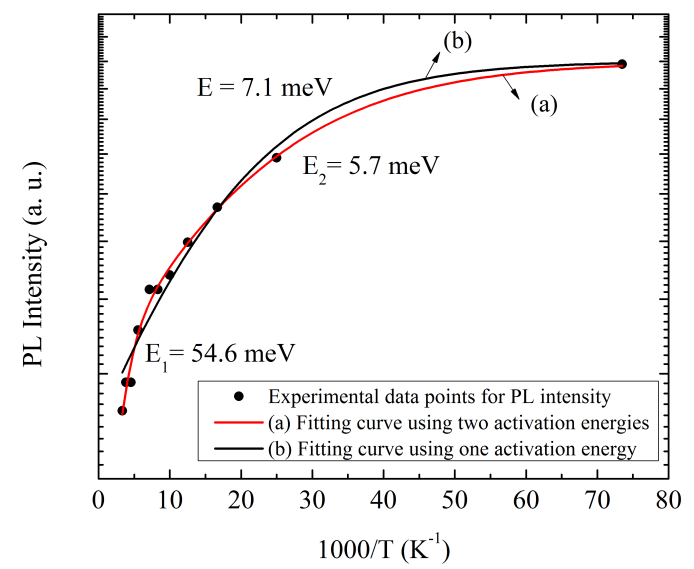

Figure 4: (Color online) Temperature dependence of photoluminescence intensity of the 1,685 nm band obtained from Fig. 3. Experimental data points were fitted with curves using Eqn. 1 and 2 . 
starts appearing below $180 \mathrm{~K}$ and becomes sharp at $13.6 \mathrm{~K}$.

The photoluminescence intensity of the two weak bands at 1,065 and 2,365 $\mathrm{nm}$ remains almost unchanged as a function of temperature whereas the photoluminescence intensity of prominent band at 1,685 nm increased exponentially with a lowering of the temperature. An explanation for this difference may be found in the origin of these luminescence bands. Perhaps the origins of the two weak bands are similar but differ from that of the 1,685 $\mathrm{nm}$ band.

To understand this further, the experimentally observed temperature dependence was fitted with the phenomenological Arrhenius equation $[35,36]$. The photoluminescence intensity of the most prominent photoluminescence band, at $1,685 \mathrm{~nm}$, as a function of temperature was measured and plotted in Figure 4. The Arrhenius plot of the photoluminescence emission using the following equation did not fit well (Fig. 4). Activation energy of $7.1 \mathrm{meV}$ was obtained when equation 1 was used for curve fitting.

$$
I_{0} / I(T)=1+A \exp (-E / k T)
$$

However, the experimental data points of photoluminescence intensity can be well fitted if two activation energies are introduced according to the following equation:

$$
I_{0} / I(T)=1+A_{1} \exp \left(-E_{1} / k_{B} T\right)+A_{2} \exp \left(-E_{2} / k_{B} T\right)
$$

where $I(T)$ is the photoluminescence intensity, $\mathrm{I}_{0}$ is photoluminescence intensity at the lowest temperature, $\mathrm{A}_{1}$ and $\mathrm{A}_{2}$ are the fitting parameters, $\mathrm{E}_{1}$ and $\mathrm{E}_{2}$ are the activation energies in the high and low temperature regions, respectively and $k_{B}$ is the Boltzmann constant. In the high temperature region, the activation energy was estimated to be $54.6 \mathrm{meV}$ whereas in the low temperature (below 100 $\mathrm{K}$ ) region it was found to be $5.7 \mathrm{meV}$. As two activation energies were found, there may be two non-radiative centers active in the luminescence quenching process. 
Table 2: Peak positions and FWHM of the NIR photoluminescence bands obtained at 13.6 and $300 \mathrm{~K}$.

\begin{tabular}{cccccc}
\hline \multicolumn{2}{c}{$\begin{array}{c}\text { Peak positions } \\
\text { Wavelength }(\mathrm{nm})\end{array}$} & \multicolumn{3}{c}{ Energy $(\mathrm{eV})$} \\
\hline $13.6 \mathrm{~K}$ & $300 \mathrm{~K}$ & $13.6 \mathrm{~K}$ & $300 \mathrm{~K}$ & $13.6 \mathrm{~K}$ & $300 \mathrm{~K}$ \\
\hline 1,066 & 1,065 & 1.16 & 1.16 & 223 & 235 \\
1,747 & 1,685 & 0.71 & 0.73 & 166 & 445 \\
2,365 & 2,365 & 0.52 & 0.52 & 170 & 180 \\
\hline
\end{tabular}

\section{Conclusion}

In this study, we reported a novel laser-excited NIR photoluminescence band at 1,650 $\mathrm{nm}$ along with weak bands at 1,065 and $2,365 \mathrm{~nm}$ in fast neutronirradiated $\mathrm{MgO} \cdot n \mathrm{Al}_{2} \mathrm{O}_{3}(n=2)$ single crystal. The new bands were not observed clearly in unirradiated and electron-irradiated samples. The band also did not appear clearly in the samples that were irradiated by fast neutrons while at $20 \mathrm{~K}$. The temperature dependence of the photoluminescence intensity was measured. Two activation energies were calculated to be 5.7 and $54.6 \mathrm{meV}$ by fitting the experimental data points of the photoluminescence intensity of the 1,650 $\mathrm{nm}$ band. The novel photoluminescence bands are possibly due to neutron-irradiation induced aggregate color centers in Spinel. To understand the origin of these novel bands we need to measure photoexcitation spectra at visible-NIR range. However, the current results would give some important insights to understand the evolution of simple point defects into the formation of aggregate color centers or metal colloids which may degrade insulating properties of Spinel. M. Malo et al. reported that surface conductivity increases in $\alpha$-alumina after $45 \mathrm{keV} \mathrm{He}^{+}$ion beam irradiation due to possible formation of $\mathrm{Al}$ colloids [37]. This may degrade the insulating properties of alumina on the surface. In case of Spinel, detection of metallic colloid would be much more challenging due to its complex structure. Significant amount of work is needed to accurately understand the formation of colloid centers. A combination of pho- 
toluminescence study with other non-destructive measurement techniques such as neutron-diffraction, electron spin resonance, synchrotron x-ray diffraction or small angle x-ray scattering could give a clear understanding of the metallic colloid formation in fast neutron-irradiated Spinel.

\section{Acknowledgment}

One of the authors gratefully acknowledges supports from Dr. Kozo Atobe and Prof. Yang Tao. This study is partially supported by the Chinese Academy of Sciences Fellowships for Young International Scientists under grant no.

2012Y1JB0007, by HIR grant, UM from Ministry of Higher Education, Malaysia (Project no. UM.C/625 /1/HIR/ MOHE/ENG/26) and also by a National Science Foundation of China MianShang Grant 11375201.

\section{References}

[1] I. Jozwik, J. Jagielski, G. Gawlik, G. Panczer, N. Moncoffre, R. Ratajczak, P. Jozwik, A. Wajler, A. Sidorowicz, L. Thome, Nucl. Intstrum. Methods Phys. Res. B 365 (2015) 273.

[2] Nan Jiang, John C.H. Spence, J. Nucl. Mater. 403 (2010) 147.

[3] A. Turos, Hj. Matzke, A. Drigo, A. Sambo, R. Falcone, Nucl. Intstrum. Methods Phys. Res. B 113 (1996) 261.

[4] C.G. Lee, T. Ohmura, Y. Takeda, S. Matsuoka, N. Kishimoto, J. Nucl. Mater. 326 (2004) 211.

[5] A. Jouini, A. Yoshikawa, A. Brenier, T. Fukuda, G. Boulon, Phys. Stat. Sol. C 3 (2007) 1380.

[6] W. A. I. Tabaza, H. C. Swart, R. E. Kroon, Physica B, 439 (2014) 109.

[7] E. Ozturk, E. Karacaoglu, J. Therm. Anal Calorim. 119 (2015) 1063. 
[8] T. Katsumata, S. Minowa, T. Sakuma, A. Yoshida, S. Komuro, H. Aizawa, ECS Solid State Lett. 3 (2014) R23.

[9] C. F. Chen, F. P. Doty, R. J. T. Houk, R. O. Loutfy, H. M. Volz, P. Yang, J. Am. Ceram. Soc 93 (2010) 2399.

[10] E. A. Raja, S. Menon, B. Dhabekar, N. S. Rawat, T. K. G. Rao, J. Lumin 129 (2009) 829.

[11] V. T. Gritsyna, I. V. Afanasyev-Charkin, and V. A. Kobyakov, J. Am. Ceram. Soc. 82 (1999) 3365.

[12] A. L. Bajor, M. Chmielewski, R. Diduszko, J. Kisielewski, T. Lukasiewicz, K. Orlinski, M. Romaniec, W. Szyrski, J. Cryst. Growth 401 (2014) 844.

[13] V. T. Gritsyna, and Yu. G. Kazarinov, Nucl. Instrum. Methods Phys. Res. B 250 (2006) 349.

[14] V. T. Gritsyna, I. V. Afanasyev-Charkin, Yu. G. Kazarinov, and K. E. Sickafus, Nucl. Instrum. Methods Phys. Res. B 218 (2004) 264.

[15] G. P. Summers, G. S. White, K. H. Lee, and J. H. Crawford, Phys. Rev. B $21(1980) 2578$.

[16] E. M. Yoshimura, E. G. Yukihara, Radiat. Meas. 41 (2006) 163.

[17] A. Ibarra, D. Bravo, F. J. Lopez, F. A. Garner, J. Nucl. Mater. 336 (2005) 156.

[18] A. Ibarra, R. Vila, F. A. Garner, J. Nucl. Mater. 233-237 (1996) 1336.

[19] J. Jagielski, P. Aubert, O. Maciejak, A. Piatkowska, S. Labdi, I. JozwikBiala, P. Jozwik, A. Wajler, Nucl. Intstrum. Methods Phys. Res. B 286 (2012) 196.

[20] V. T. Gritsyna, I. V. Afanasyev-Charkin, V. A. Kobyakov, and K. E. Sickafus, J. Nucl. Mater. 283-287 (2000) 927. 
[21] A. Ibarra, D. Bravo, M. A. Garcia, J. Liopis, F. J. Lopez, and F. A. Garner, J. Nucl. Mater. 258-263 (1998) 1902.

[22] A. Z. M. S. Rahman, X. Cao, L. Wei, B. Wang, Y. Tao, Q. Xu, K. Atobe, Nucl. Instrum. Methods Phys. Res. B 305 (2013) 33.

[23] A. Z. M. S. Rahman, T. Awata, N. Yamashita, Qiu Xu, and K. Atobe, Radiat Eff. Def. Solids 164 (2009) 692.

[24] A. Z. M. S. Rahman, T. Awata, N. Yamashita, Y. Inada, K. Oshima, Q. $\mathrm{Xu}$, and K. Atobe, Physics Procedia 2 (2009) 551.

[25] S. Sawai, T. Uchino, J. Appl. Phys. 112 (2012) 103523-1-6.

[26] G. Krexner, M. Prem, F. Beuneu, P. Vajda, App. Phys. Lett. 91 (2003) 135502-1.

[27] M. Izerrouken, N. Souami, L. Guerbous, S. Djaroum, M. Kadouma, A. Sari, A. Meftah, Nucl. Instrum. Methods Phys. Res. B 266 (2008) 2745.

[28] M Prem, G Krexner, F Beuneu, P Vajda, Physica B 350 (2004) E999.

[29] E. A. Kotomin, V. N. Kuzovkov, A. I. Popov, R. Vila, Nucl. Instrum. Methods Phys. Res. B doi:10.1016/j.nimb.2015.08.055.

[30] A. Z. M. S. Rahman, X. Cao, L. Wei, B. Wang, H. Ji, T. Yang, Q. Xu, K. Atobe, Phil. Mag. Lett. 94 (2014) 211.

[31] A. Z. M. S. Rahman, L. Wei, T. Yang, Q. Xu, K. Atobe, Phys. Stat. Sol. A $211(2014) 1535$.

[32] Z. He, and P. Jung, Nucl. Intstrum. Methods Phys. Res. B 166-167 (2000) 165.

[33] A. Z. M. S. Rahman, Z. Li, X. Cao, B. Wang, Q. Xu, K. Atobe, Nucl. Instrum. Methods Phys. Res. B 335 (2014) 70.

[34] M. Okada, K. Atobe and M. Nakagawa, Nucl. Instrum. Methods Phys. Res. B 226 (2004) 369. 
[35] M. Leroux, N. Grandjean, B. Beaumont, G. Nataf, F. Semond, J. Massies and P. Gibart, J. Appl. Phys. 86 (1999) 3721.

[36] G. W. Shu, P. F. Wu, M. H. Lo and J. L. Shen, T. Y. Lin, H. J. Chang, Y. F. Chen, C. F. Shih, C. A. Chang and N. C. Chen, Appl. Phys. Lett. 89 (2006) 131913-1.

[37] M. Malo, A. Moroo, E.R. Hodgson, Fusion Eng. Des. 89 (2014) 2179. 